\title{
Nitrate removal using Purolite A520E ion exchange resin: batch and fixed-bed column adsorption modelling
}

\author{
T. Nur • W. G. Shim • P. Loganathan • \\ S. Vigneswaran · J. Kandasamy
}

Received: 26 March 2013/Revised: 26 November 2013/ Accepted: 11 January 2014/Published online: 29 January 2014

(C) Islamic Azad University (IAU) 2014

\begin{abstract}
Removing excessive nitrate from water is essential because it causes eutrophication which in turn has a harmful effect on aquatic life, resulting in a reduction in biodiversity and posing a danger to people's health when the water is used for drinking. In this study, nitrate removal from aqueous solutions was studied using an ion exchange resin (Purolite A520E) in batch and fixed-bed column experiments. Batch adsorption kinetics was very well described by pseudo-first-order, pseudo-second-order and homogeneous surface diffusion models for resin doses 1.5 and $3.0 \mathrm{~g} / \mathrm{L}$ at a nitrate concentration $20 \mathrm{mg} \mathrm{N} / \mathrm{L}$. Column kinetic data satisfactorily fitted to the empirical Thomas model and a numerical model based on advectiondispersion equation for filtration velocities 2.5 and $5.0 \mathrm{~m} / \mathrm{h}$ at a column height of $12 \mathrm{~cm}$ and inlet concentration $20 \mathrm{mg} \mathrm{N} / \mathrm{L}$. The experimental and Thomas model predicted breakthrough adsorption capacity ranges for the two filtration rates were $12.0-13.5$ and $8.2-9.7 \mathrm{mg} \mathrm{N} / \mathrm{g}$, respectively, whereas the maximum adsorption capacity determined using Langmuir adsorption isotherm model in the batch study was $32.2 \mathrm{mg} \mathrm{N} / \mathrm{g}$.
\end{abstract}

Keywords Adsorption models · Ion exchange resin . Fixed-bed column · Breakthrough curve · Advectiondispersion equation · Purolite A520E

T. Nur · P. Loganathan $\cdot$ S. Vigneswaran $(\bowtie) \cdot J$. Kandasamy Faculty of Engineering and Information Technology, University of Technology, Sydney, Broadway, NSW 2007, Australia e-mail: s.vigneswaran@uts.edu.au

W. G. Shim

School of Applied Chemical Engineering, Chonnam National University, Kwangju 500-757, Korea

\section{Introduction}

Nitrate is an essential nutrient for the growth of plants and microorganisms. However, excessive concentration of nitrate in water affects aquatic environment and causes health hazards for people. Nitrate contamination of water is one of the most serious environmental and health problems worldwide. High nitrate concentration in water can cause eutrophication which is a serious environmental problem as it can lead to abundant development of aquatic plants, growth of algae, have harmful effects on fish and other aquatic life and disturb the ecological balance of organisms present in water. Furthermore, the presence of excessive nitrate ions in drinking water is a potential public health hazard as it can cause infant methemoglobinemia, otherwise known as "blue baby" syndrome (Fewtrell 2004). Moreover, the formation of nitrate compounds in the stomach has been shown to be carcinogenic (Chiu et al. 2007). Owing to these adverse effects of nitrate, the World Health Organization (WHO 2006) accepted the maximum allowable nitrate concentration in drinking water as $50 \mathrm{mg} \mathrm{NO}_{3}{ }^{-} / \mathrm{L}$ (11.3 mg N/L) (WHO 2006). Therefore, nitrate is a water pollutant under regulation, and it is necessary to reduce its concentration prior to discharge or being used for drinking.

Nitrate is a stable and highly soluble ion which makes it difficult to remove using conventional water treatment methods such as precipitation and adsorption. Of the various techniques available for removing nitrate, the ion exchange/adsorption process is the most suitable for small water suppliers contaminated by nitrate (Bhatnagar and Sillanpää 2011). This is due to its simplicity, effectiveness and relatively low cost (Bhatnagar and Sillanpää 2011). Ion exchange/adsorption methods also have the 
ability to handle shock loadings and can operate over a wide range of temperatures.

Several materials such as fly ash, cement, surfactantmodified zeolite, alunite, polymeric ion exchangers and agricultural residues have been investigated as adsorbents for the removal of nitrate anions (Orlando et al. 2002; Bhatnagar and Sillanpää 2011). Of these, strong base anion exchange resins have been generally found to have high adsorption capacity for nitrate (Kapoor and Viraraghavan 1997). However, the selectivity of adsorption of nitrate by these resins in the presence of other anions varied depending on the length of carbon chain in the resin. The higher the carbon chain length of the functional group in the resin, higher the selectivity of nitrate adsorption. This is explained as due to longer carbon chain making the resin more hydrophobic, and thus, the resin become more selective in adsorbing anions such as nitrate with lower hydration energies (Valincius et al. 2004). Gu et al. (2004) using Purolite A520E resin having triethylamine functional group showed that the selectivity of adsorption of anions followed the order $\mathrm{NO}_{3}{ }^{-}>\mathrm{Cl}^{-}>\mathrm{SO}_{4}{ }^{2-}$, which is the reverse order of their hydration energies (Valincius et al. 2004). Kapoor and Viraraghavan (1997) reported that the nitrate to sulphate selectivity increased from a factor of 100-1,000 when the ammonium nitrogen in the resin was surrounded by ethyl groups in place of methyl groups.

A variety of anion exchange resins have been used for selectively removing nitrate, such as Purolite A520E (Samatya et al. 2006; Primo et al. 2009), Purolite A100 (Bulgariu et al. 2010), Purolite A300 (Primo et al. 2009) and macro-reticuled Amberlite IRA900 (Pintar et al. 2001). Nur et al. (2012) used two anion exchange resins, Purolite A520E and Purolite A500PS, for the simultaneous removal of nitrate and phosphate from synthetic water using batch studies and found that both the Purolites preferentially removed nitrate over phosphate from solutions containing these two ions at various concentration ratios, and hence, they considered that these resins to be nitrate selective. However, the nitrate selectivity for adsorption was higher for Purolite A520E than Purolite A500PS. Johir et al. (2011) also obtained similar results for these two Purolites using column adsorption experiments on MBR effluents from natural wastewater.

The characteristics of adsorption behaviour on resins are generally inferred in terms of both adsorption kinetics and equilibrium isotherms. Samatya et al. (2006) used the ion exchange resin Purolite A520E to remove nitrate from water and found that this resin elicited promising results for batch and column-mode removal of nitrate from ground water. By fitting their data to the Langmuir adsorption isotherm, they reported the maximum adsorption value of $18.5 \mathrm{mg} \mathrm{N} / \mathrm{g}$ dry resin. Most studies on nitrate removal by ion exchange resins have been performed in batch experiments, and only a few have been reported in fixed-bed systems (Hoek et al. 1988; Hekmatzadeh et al. 2012). Although batch experiments are useful in comparing adsorption capacities among adsorbents within a short period of time and obtaining information on the effects of many solution variables on adsorption, they have a disadvantage in that they do not provide information about the hydrodynamic parameters of fixed-bed columns such as the dispersion coefficient (Loganathan et al. 2014). Another drawback is their discontinuity and the need to perform complicated phase separation operations (Zagorodni 2007). Fixed-bed column experiments, on the other hand, do not have the above drawbacks, and the results of such experiments can be directly applied to: firstly, obtain reliable solutions to design optimization; and secondly, predict the breakthrough curves of fixedbed columns in real water treatment processes.

In this paper, the removal efficiency of nitrate through the use of a selective ion exchange resin, Purolite A520E, in both batch and fixed-bed systems was investigated. The effects of filtration velocity on nitrate removal were also analysed. The objectives of this study were divided into four parts: (1) analysis of the kinetic and equilibrium adsorption isotherms of nitrate on four ion exchange resins and justify the selection of Purolite A520E for a detailed study; (2) model batch adsorption data by pseudo-firstorder, pseudo-second-order and homogeneous surface diffusion models; (3) examine the breakthrough curves for the adsorption of nitrate using Thomas model; and (4) develop a numerical model based on advection-dispersion equation and simulating the equilibrium and model parameters to describe the column adsorption data. This is the first study on modelling nitrate adsorption in both batch and fixed-bed column trials using Purolite A520E. The study was conducted in the Environmental Research laboratory of the University of Technology, Sydney, during the years 2011 and 2012.

\section{Materials and methods}

Ion exchange resins

Four ion exchange resins, namely Purolite A520E, Purolite A500P, Purolite FerrIX A33E and Dowex 21k, 
were used as adsorbents. Purolite A520E is a macroporous strong base anion exchange resin consisting of macroporous polystyrene cross-linked divinylbenzene with a triethylamine functional group and specially designed to remove nitrates from water for potable purposes (Gu et al. 2004; Purolite 2013). Purolite A500PS is also a macroporous strong base anion exchanger but consists of styrene-divinylbenzene with a trimethylamine functional group and designed for use as an organic scavenger, e.g., for the removal of tannins, fulvic and humic acids, from domestic effluents (Ahmad et al. 2012; Purolite 2013). From previous study, it was found that this resin also had a good phosphate as well as nitrate ion exchange capacity (Johir et al. 2011). Purolite FerrIX A33E resin, previously called Arsen$\mathrm{Xnp}$, is a hybrid strong base anion exchange resin with quaternary ammonium functional groups blended with hydrous iron oxide nanoparticles that have a very high attraction for arsenic (Zagorodni 2007). Recently Nur et al. (2014) observed that this resin had a high capacity to remove phosphate from water. However, its capacity to remove nitrate is not known. If this resin has also the capacity to remove nitrate, it will be a potential adsorbent to remove multianions contaminants. Dowex $21 \mathrm{~K}$ $\mathrm{XLT}$ is another strong base anion exchange resin composed of Styrene-DVB with trimethylamine functional groups (Sigmaaldrich 2013). This resin has been used to effectively remove uranium from groundwater at low nitrate concentration but not at high nitrate concentration (Phillips et al. 2008). This may be due to the resin having high affinity towards nitrate, but no study has been conducted on the nitrate removal effectiveness of this resin. All four resins had $\mathrm{Cl}^{-}$as the exchangeable anion in the as-received form.

\section{Feed solution}

The feed solution used was distilled water spiked with predetermined amounts of nitrate. Solutions with different concentrations of nitrate $(10-50 \mathrm{mg} \mathrm{N} / \mathrm{L})$ were prepared using Analar grade $\mathrm{KNO}_{3}$.

\section{Chemical analysis}

The analysis of nitrate ion was carried out using a Metrohm ion chromatograph (model 790 Personal IC) equipped with an autosampler and conductivity cell detector. The separation was achieved using an A SUPP column 3 $(150 \mathrm{~mm} \times 4 \mathrm{~mm}) . \mathrm{Na}_{2} \mathrm{CO}_{3}(3.2 \mathrm{mmol} / \mathrm{L})$ and $\mathrm{NaHCO}_{3}$ $(1.0 \mathrm{mmol} / \mathrm{L})$ were used as mobile phase with a flow rate of $0.9 \mathrm{~mL} / \mathrm{min}$.
Batch adsorption studies

\section{Adsorption kinetics}

Batch adsorption kinetic experiments were conducted with two concentrations of ion exchange resins ( 1.5 and $3 \mathrm{~g} / \mathrm{L})$ at a nitrate concentration of $20 \mathrm{mg} \mathrm{N} / \mathrm{L}$ in a set of glass flasks containing $100 \mathrm{~mL}$ of nitrate solution. The suspensions were agitated in a flat shaker at a shaking speed of $120 \mathrm{rpm}$ for $6 \mathrm{~h}$ at room temperature $\left(24 \pm 1^{\circ} \mathrm{C}\right)$. The aqueous samples were taken at different time intervals, and the concentrations of nitrate were measured. The amount of nitrate adsorption at time $t, q_{\mathrm{t}}(\mathrm{mg} \mathrm{N} / \mathrm{g})$, was calculated using Eq. (1):

$q_{t}=\frac{\left(C_{0}-C_{t}\right) V}{M}$

where $C_{0}=$ initial concentration of nitrate $(\mathrm{mg} \mathrm{N} / \mathrm{L})$; $C_{t}=$ concentration of nitrate at time $t(\mathrm{mg} \mathrm{N} / \mathrm{L}) ; V=$ volume of the solution (L); and $M=$ mass of dry adsorbent $(\mathrm{g})$.

Removal efficiency was calculated using Eq. (2):

Removal efficiency $(\%)=\frac{\left(C_{0}-C_{t}\right)}{C_{0}} \times 100$

\section{Equilibrium adsorption isotherm}

Equilibrium adsorption experiments were conducted in a set of glass flasks with $100 \mathrm{~mL}$ solutions spiked with nitrate $(20 \mathrm{mg} \mathrm{N} / \mathrm{L})$ and different ion exchange resin concentrations of $0.1-10 \mathrm{~g} / \mathrm{L}$ at room temperature $\left(24 \pm 1{ }^{\circ} \mathrm{C}\right)$. The suspensions were agitated in a flat shaker at a shaking speed of $120 \mathrm{rpm}$ for $72 \mathrm{~h}$ to ensure that the adsorption equilibrium is reached. The experiments were duplicated, and the average values were taken. The difference between duplicate values was within $\pm 2 \%$. The amount of nitrate adsorption at equilibrium, $q_{\mathrm{e}}(\mathrm{mg} \mathrm{N} / \mathrm{g})$, was calculated using Eq. (3),

$q_{\mathrm{e}}=\frac{\left(C_{0}-C_{\mathrm{e}}\right) V}{M}$

where $C_{0}=$ initial concentration of nitrate $(\mathrm{mg} \mathrm{N} / \mathrm{L})$; $C_{\mathrm{e}}=$ equilibrium concentration of nitrate $(\mathrm{mg} \mathrm{N} / \mathrm{L})$; $V=$ volume of the solution (L); and $M=$ mass of adsorbent $(\mathrm{g})$.

The Langmuir adsorption model (Eq. 4) was used to describe the equilibrium adsorption data:

$Q_{\mathrm{e}}=\frac{q_{\mathrm{max}} K_{\mathrm{L}} C_{\mathrm{e}}}{1+K_{\mathrm{L}} C_{\mathrm{e}}}$

where $q_{\max }=$ the maximum amount of the nitrate-N concentration per unit weight of the adsorbent $(\mathrm{mg} \mathrm{N} / \mathrm{g})$, $K_{\mathrm{L}}=$ Langmuir adsorption constant $(\mathrm{L} / \mathrm{mg})$. 
A plot of $C_{\mathrm{e}} / Q_{\mathrm{e}}$ versus $C_{\mathrm{e}}$ was used to calculate $q_{\max }$ according to Eq. (5) (Fatima et al. 2013)

$C_{\mathrm{e}} / Q_{\mathrm{e}}=1 / q_{\max } K_{\mathrm{L}}+C_{\mathrm{e}} / q_{\max }$.

Fixed-bed column studies

A fixed-bed column was prepared by a method similar to that of Awual et al. $(2008,2013)$ but without prior leaching of column with $\mathrm{HCl}$ to convert the adsorbent to a $\mathrm{Cl}^{-}$form. This was not done in the current study because the Purolite A520E was supplied by the manufacturer already in a $\mathrm{Cl}^{-}$form (Purolite 2013). The column was made-up of a Pyrex glass tube with an inner diameter of $2.0 \mathrm{~cm}$. A sample of dried Purolite $(38 \mathrm{~g})$ was carefully packed into the column by lightly pressing with a glass rod to yield the desired bed height of $12 \mathrm{~cm}$. The total volume of ion exchange resin was $37.7 \mathrm{~mL}$, which was used as reference volume in the conversion of volume of feeds to bed volumes (BV). At the bottom of the filtration column (underneath the ion exchange resin), glass beads with a height of $2 \mathrm{~cm}$ was placed in order to provide a uniform flow of the solution through the column. The experiments were conducted at room temperature $\left(24 \pm 1{ }^{\circ} \mathrm{C}\right)$ by using an up-flow mode of filtration at velocities of 2.5 and $5.0 \mathrm{~m} / \mathrm{h}$ controlled by a peristaltic pump. The concentration of nitrate in synthetic feed solution was $20 \mathrm{mg} \mathrm{N} / \mathrm{L}$. The effluent samples were collected at regular time intervals and subjected to nitrate analysis.

The breakthrough curves in the fixed-bed column show the loading behaviour of nitrate to be removed from the solution and are usually expressed in terms of adsorbed nitrate- $\mathrm{N}$ concentration $\left(C_{\mathrm{ad}}\right)$, inlet nitrate-N concentration $\left(C_{\mathrm{o}}\right)$, outlet nitrate- $\mathrm{N}$ concentration $(C)$ or normalized concentration defined as the ratio of outlet nitrate concentration to inlet nitrate concentration $(\mathrm{Cl}$ $C_{\mathrm{o}}$ ) as a function of time. The maximum column capacity, $q_{\text {total }}(\mathrm{mg} \mathrm{N})$, for a given feed concentration and flow rate is equal to the area under the plot of the adsorbed nitrate- $\mathrm{N}$ concentration, $C_{\mathrm{ad}}\left(C_{\mathrm{ad}}=C_{\mathrm{o}}-C\right)$ $(\mathrm{mg} / \mathrm{L})$ versus effluent time $(t, \mathrm{~min})$ and is calculated from Eq. (6)

$q_{\text {total }}=\frac{Q}{1,000} \int_{t=0}^{t=\text { total }} C_{\text {ad }} \mathrm{d} t$

Equilibrium uptake $q_{\mathrm{eq}}(\mathrm{mg} \mathrm{N} / \mathrm{g})$ or maximum capacity of the column is defined by Eq. (7) as the total amount of adsorbed nitrate- $\mathrm{N}\left(q_{\text {total }}\right)$ per gram of adsorbent $(w)$ at the end of the total flow time: $q_{\mathrm{eq}}=\frac{q_{\text {total }}}{w}$

Batch kinetic modelling

Pseudo-first-order kinetics model

The equation for the pseudo-first-order kinetic model can be expressed as below (Aliabadi et al. 2012):

$\frac{\mathrm{d} q_{t}}{\mathrm{~d} t}=k_{1}\left(q_{\mathrm{e}}-q_{t}\right)$

where $q_{\mathrm{e}}=$ amount of nitrate adsorbed at equilibrium $(\mathrm{mg} \mathrm{N} / \mathrm{g}) q_{t}=$ amount of nitrate adsorbed at time, $t(\mathrm{~min})$ $(\mathrm{mg} \mathrm{N} / \mathrm{g})$ and $k_{1}=$ equilibrium rate constant of pseudofirst-order adsorption (1/min).

\section{Pseudo-second-order kinetics model}

The pseudo-second-order kinetic model (Ho and McKay 1999; Aliabadi et al. 2012) is described by the following equation:

$\frac{\mathrm{d} q_{t}}{\mathrm{~d} t}=k_{2}\left(q_{\mathrm{e}}-q_{t}\right)^{2}$

where $q_{\mathrm{e}}=$ amount of nitrate adsorbed at equilibrium $(\mathrm{mg} \mathrm{N} / \mathrm{g}) q_{\mathrm{t}}=$ amount of nitrate adsorbed at time, $t(\mathrm{~min})$ $\left(\mathrm{mg} \mathrm{N} / \mathrm{g}\right.$ ) and $k_{2}=$ equilibrium rate constant of pseudosecond-order adsorption ( $\mathrm{g} / \mathrm{mg} \mathrm{min}$ ).

\section{HSDM adsorption kinetics model}

The HSDM used to describe the kinetics of adsorption of nitrate on Purolite A520E has three steps: (1) diffusion of nitrate through a stagnant liquid film layer covering the Purolite particle; (2) adsorption of nitrate from the liquid phase onto the outer surface of the Purolite particle; and (3) diffusion of nitrate along the inner surface of the Purolite particles until it reaches its adsorption site (Najm 1996). The equation used in the model is:

$\frac{\partial q}{\partial t}=D_{\mathrm{s}}\left(\frac{\partial^{2} q}{\partial r^{2}}+\frac{2}{r} \frac{\partial q}{\partial r}\right)$

Initial and boundary conditions are:

$$
\begin{array}{ll}
t=0 ; \quad q=0 \\
r=0 ; \quad \frac{\partial q}{\partial r}=0 \\
r=r_{\mathrm{p}} ; \quad D_{\mathrm{s}} \rho_{\mathrm{p}} \frac{\partial q}{\partial r}=k_{\mathrm{f}}\left(C-C_{\mathrm{s}}\right)
\end{array}
$$


where $q$ is surface concentration at any radial distance ( $r$ ) from the centre of the particle during adsorption, $\mathrm{mg} \mathrm{N} /$ $\mathrm{g} ; D$, the surface diffusion coefficient (the rate of diffusion of the nitrate along the surface of the adsorbent), $\mathrm{m}_{2} / \mathrm{s} ; k$, the external mass transfer coefficient, $\mathrm{m} / \mathrm{s} ; \rho$, the apparent density of the adsorbent, $\mathrm{kg} / \mathrm{m}_{3} ; C$, the bulk phase concentration, $\mathrm{mg} \mathrm{N} / \mathrm{L} ; C$ is the concentration on the external surface, $\mathrm{mg} \mathrm{N} / \mathrm{L}$.

In this work, Freundlich equation was used as the boundary condition in HSDM calculations. The fit of the equilibrium data to Freundlich adsorption isotherm and the isotherm parameters obtained were presented in our previous study (Nur et al. 2012). Using the isotherm parameters and Eqs. (10-13), $k_{\mathrm{f}}$ and $D_{\mathrm{s}}$ were calculated.

An orthogonal collocation method (OCM) and a variable coefficient ordinary differential equation solver (VODE) were used to solve Eqs. (10-13) as described for modelling of organic matter removal using Purolite A500PS by Ahmad et al. (2012). The partial differential equations of the batch system were first transformed
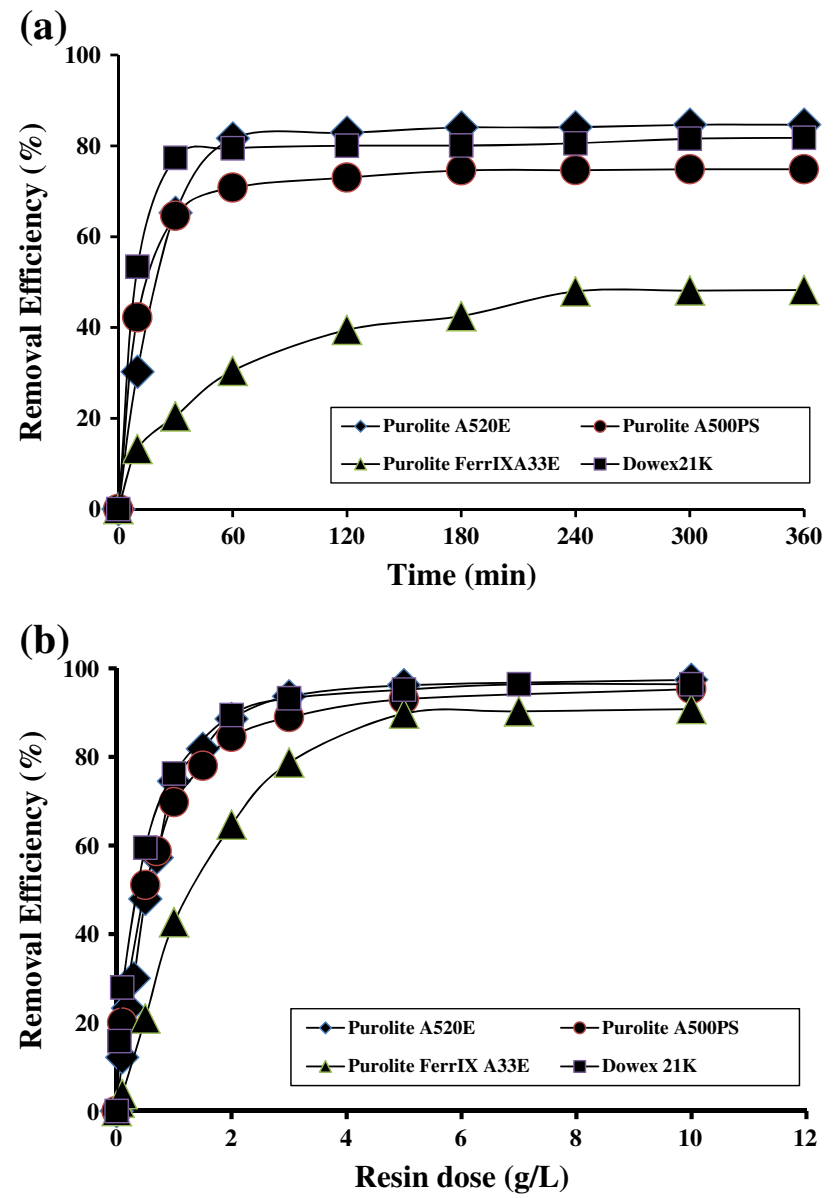

Fig. 1 Effect of a contact time on the removal of nitrate (initial $\mathrm{NO}_{3}-$ $\mathrm{N}$ concentration of $20 \mathrm{mg} / \mathrm{L}$ and resin dose $1.5 \mathrm{~g} / \mathrm{L}$ ). b Resin dose on the removal of nitrate (initial nitrate concentration $20 \mathrm{mg} \mathrm{N} / \mathrm{L}$ ) into ordinary differential equations. The resulting equations were then integrated numerically in the time domain. Nelder-Mead simplex algorithm technique (Guo et al. 2005), which is based on minimizing the differences between the experimental and predicted adsorption values as a function of time, was used to estimate the values of $D_{\mathrm{s}}$ and $K_{\mathrm{f}}$. The minimization of the differences was performed using the following object function:

Minimum $=\sum_{j}\left(C_{\exp , j}-C_{\mathrm{cal}, ~_{j}}\right)^{2}$

where $C_{\exp , j}$ is the experimental nitrate concentration data and $C_{\mathrm{cal}, j}$ is the calculated nitrate concentration. A detailed explanation to this method is given elsewhere (Villadsen and Stewart 1967; Brown et al. 1989; Guo et al. 2005).

Fixed-bed column modelling

\section{Thomas model}

Thomas model (Thomas 1944) assumes plug flow behaviour in the bed and uses the Langmuir isotherm for equilibrium and second-order reversible reaction kinetics. This model is suitable for adsorption processes, where the external and internal diffusion limitations are absent. The model is given by:

$\ln \left(\frac{C_{\mathrm{o}}}{C}-1\right)=\frac{k_{\mathrm{T}} q_{\mathrm{o}} m_{\mathrm{c}}}{Q}-k_{\mathrm{T}} C_{\mathrm{o}} t$

where $k_{\mathrm{T}}$ is the Thomas rate constant ( $\left.\mathrm{L} / \mathrm{min} \mathrm{mg}\right), q_{0}$ is the maximum solid-phase concentration of the solute $(\mathrm{mg} / \mathrm{g})$, $m_{\mathrm{C}}$ is the mass of adsorbent in the column $(\mathrm{g})$ and $Q$ is the volumetric flow rate $(\mathrm{L} / \mathrm{min})$. The values for $k_{\mathrm{T}}$ and $q_{0}$ were determined from the slope and intercept, respectively, of a linear plot of $\ln \left(C_{0} / C-1\right)$ versus $t$.

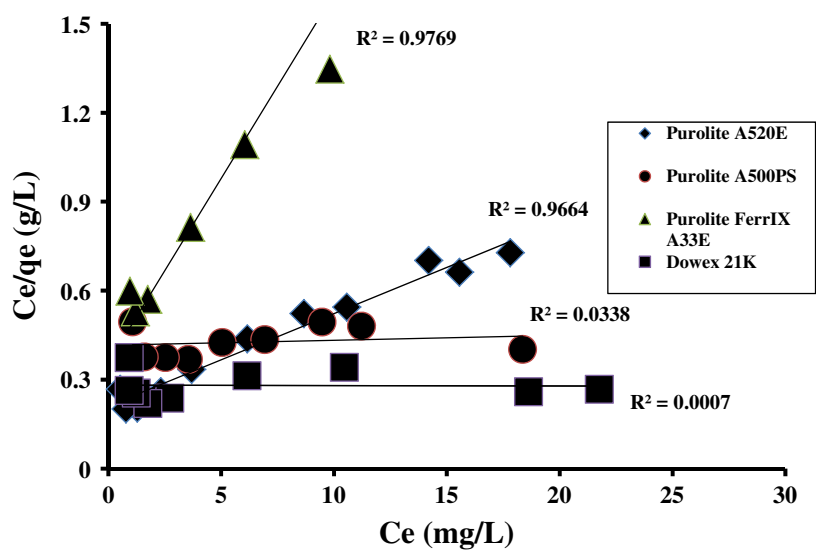

Fig. 2 Langmuir plots of equilibrium adsorption of nitrate 


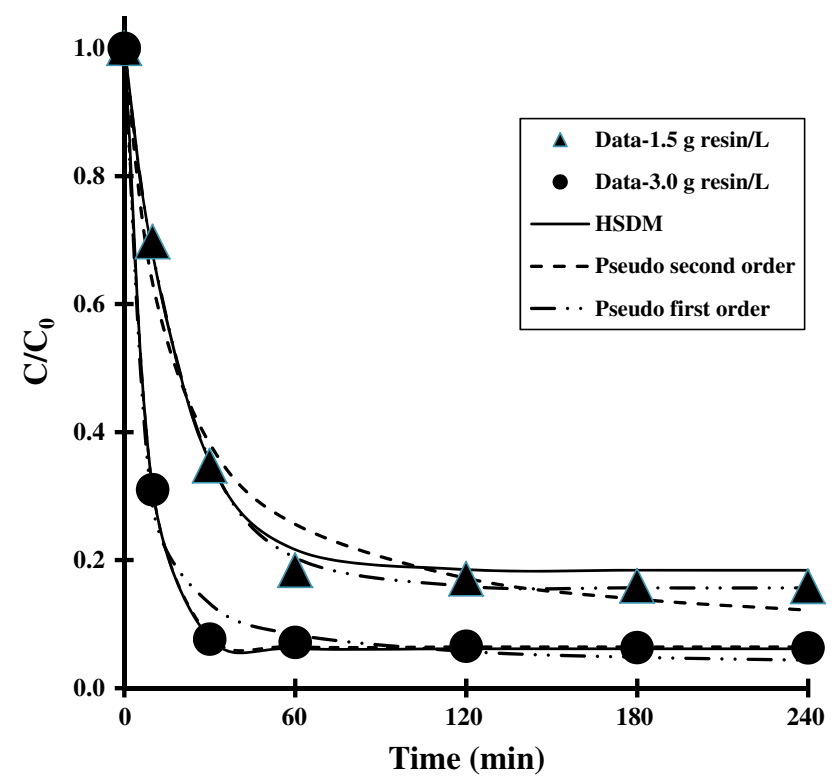

Fig. 3 HSDM, pseudo-first-order and pseudo-second-order kinetic model predictions of the experimental data for the adsorption of nitrate onto Purolite A520E (resin doses 1.5 and $3.0 \mathrm{~g} / \mathrm{L}$ ). Experimental values are shown by data points, and model predictions are represented by lines

\section{Numerical model}

The mass balance equations and the boundary conditions of the fixed-bed system are given by the following equations, which were previously described (Ruthven 1984; Guo et al. 2005; Ahmad et al. 2012).

$-D_{\mathrm{L}} \frac{\partial^{2} C}{\partial z^{2}}+v \frac{\partial C}{\partial z}+\frac{\partial C}{\partial t}+\frac{1-\varepsilon_{\mathrm{B}}}{\varepsilon_{\mathrm{B}}} \rho_{s} \frac{\partial q}{\partial t}=0$

where $D_{\mathrm{L}}=$ axial dispersion coefficient $\left(\mathrm{m}^{2} / \mathrm{s}\right), C=$ concentration in bulk solution $(\mathrm{mg} / \mathrm{L}), v=$ velocity of the fluid $(\mathrm{m} / \mathrm{s}), z=$ bed depth $(\mathrm{m}), \varepsilon_{\mathrm{b}}=$ bed porosity.
The above equation can be solved by using the initial and boundary conditions, $C=0$ and $z=0$,

$\left.D_{\mathrm{L}} \frac{\partial C}{\partial z}\right|_{z=0}=-v\left(\left.C\right|_{z=0^{-}}-\left.C\right|_{z=0^{+}}\right)$

and at $z=L$,

$\left.\frac{\partial C}{\partial z}\right|_{z=\mathrm{L}}=0$

The $D_{\mathrm{s}}$ values depend only on the influent nitrate concentration. Therefore, the $D_{\mathrm{s}}$ values derived from the batch kinetic experiments were used in the fixed-bed simulation (Eq. 10). On the other hand, in batch mode adsorption experiments, $k_{\mathrm{f}}$ depends on the agitation speed, but in fixed-bed system, it is a function of Reynolds $\left(R_{e}\right)$ and Schmidt $\left(S_{c}\right)$ numbers. Hence, $k_{\mathrm{f}}$ will not be the same as that derived from batch kinetics data. Therefore, $k_{\mathrm{f}}$ was determined by matching the fixed-bed experimental data with values derived from the theoretical equations. Axial dispersion coefficient, $D_{\mathrm{L}}$, was also determined by this procedure.

\section{Results and discussion}

Comparison of nitrate adsorption by different ion exchange resins

Initially, batch kinetic and equilibrium experiments were conducted with four ion exchange resins, namely Purolite A500PS, Purolite A520E, Purolite FerrIX A33E and Dowex $21 \mathrm{~K}$. Batch kinetic experiments at a resin concentration of $1.5 \mathrm{~g} / \mathrm{L}$ showed that the adsorption capacity increased with contact time up to $120 \mathrm{~min}$ and became steady afterwards for all resins (Fig. 1a), except Purolite FerrIX A33E. For Purolite FerrIX A33E, equilibrium was
Table 1 Batch study HSDM, pseudo-first-order (PFO) and pseudo-second-order (PSO) kinetics model parameters for the adsorption of nitrate onto Purolite A520E

\begin{tabular}{lllllll}
\hline & $q_{\mathrm{e}}(\mathrm{mg} / \mathrm{g})$ & $K_{1}(1 / \mathrm{min})$ & $K_{2}(1 / \mathrm{min})$ & $K_{\mathrm{f}}(\mathrm{m} / \mathrm{s})$ & $D_{\mathrm{s}}\left(\mathrm{m}^{2} / \mathrm{s}\right)$ & $R^{2}$ \\
\hline $1.5 \mathrm{~g}$ Resin/L & & & & & \\
Experimental & 11.0 & & & & \\
PFO & 10.9 & $4.81 \times 10^{-2}$ & & & & 0.99 \\
PSO & 12.1 & & $5.37 \times 10^{-3}$ & & 0.99 \\
HSDM & & & $1.40 \times 10^{-5}$ & $9.37 \times 10^{-9}$ & 0.99 \\
3.0 g Resin/L & & & & & \\
Experimental & 5.7 & & & & \\
PFO & 5.6 & $13.0 \times 10^{-2}$ & & & & 0.99 \\
PSO & 5.8 & & $4.86 \times 10^{-2}$ & & & 0.99 \\
HSDM & & & $9.08 \times 10^{-6}$ & $2.26 \times 10^{-9}$ & 0.99 \\
\hline
\end{tabular}


reached only after $300 \mathrm{~min}$. Purolite A520E demonstrated maximum removal efficiency (about $84 \%$ ) within $2 \mathrm{~h}$.

The results of equilibrium experiment for four resins showed that the removal efficiency of nitrate improved with increased resin dose due to increased availability of surface area for adsorption (Fig. 1b). Of the four resins, Purolite A520E and Dowex 21k had very high (around 75 and $70 \%$, respectively) removal efficiency at a low resin dose of $1.0 \mathrm{~g} / \mathrm{L}$. These results imply that a very low dose of ion exchange resin can easily remove high amounts of nitrate from wastewater. As in the kinetic study (Fig. 1a), Purolite A520E had the highest removal efficiency. Of these four resins, the data for only Purolite A520E and Purolite FerrIX A33E satisfactorily fitted to the Langmuir Isotherm equation with the maximum adsorption capacity of 32.2 and $8.77 \mathrm{mg} \mathrm{N} / \mathrm{g}$, respectively (Fig. 2). Because Purolite A520E had the highest removal efficiency of nitrate, it was chosen for further testing and modelling.

The main mechanism of adsorption of nitrate on Purolite A520E is electrostatic interaction or coulombic forces between the positively charged quaternary ammonium functional group in the resin and the negatively charged $\mathrm{NO}_{3}{ }^{-}$in solution (Helfferich 1995; Gu et al. 2004). During adsorption, $\mathrm{NO}_{3}{ }^{-}$exchanged with $\mathrm{Cl}^{-}$, which was already adsorbed onto the resin by an ion exchange process (Primo et al. 2009). The ethylamine-based quaternary ammonium functional group in Purolite A520E is more hydrophobic than the methylamine-based quaternary ammonium functional group in some of the other ion exchange resins, and therefore, it selectively adsorbs anions having lower hydration energies (Gu et al. 2004). Because $\mathrm{NO}_{3}{ }^{-}$has lower hydration energy than $\mathrm{SO}_{4}{ }^{2-}$, it is expected to be preferentially adsorbed in the presence of $\mathrm{SO}_{4}{ }^{2-}$ on Purolite A520E, despite the latter anion has a higher number of charges (Kapoor and Viraraghavan 1997; Gu et al. 2004; Samatya et al. 2006).

Table 2 Coulmn study model parameters and statistical estimations for two filtration rates (bed height $=12 \mathrm{~cm}$ and initial concentration $=20 \mathrm{mg} \mathrm{N} / \mathrm{L}$ )

\begin{tabular}{llll}
\hline Model & Parameter & $V=2.5 \mathrm{~m} / \mathrm{h}$ & $V=5.0 \mathrm{~m} / \mathrm{h}$ \\
\hline Thomas & $k_{\mathrm{T}}(\mathrm{L} / \mathrm{mg} \min )$ & 0.098 & 0.193 \\
& $q_{0}(\mathrm{mg} / \mathrm{g})$ & 9.69 & 8.22 \\
& $R^{2}$ & 0.96 & 0.99 \\
Numerical modelling & $D_{\mathrm{s}}\left(\mathrm{m}^{2} / \mathrm{s}\right)$ & $6.50 \times 10^{-8}$ & $6.60 \times 10^{-8}$ \\
& $k_{\mathrm{f}}(\mathrm{m} / \mathrm{s})$ & $9.25 \times 10^{-7}$ & $1.85 \times 10^{-6}$ \\
& $D_{\mathrm{L}}\left(\mathrm{m}^{2} / \mathrm{s}\right)$ & $1.00 \times 10^{-6}$ & $5.50 \times 10^{-6}$ \\
& $R^{2}$ & 0.98 & 0.99 \\
\hline
\end{tabular}

Batch adsorption kinetics modelling

In adsorption kinetics, mass transfer and diffusion of adsorbate particles from bulk liquid phase to adsorbent surface determine the rate of adsorption. Figure 3 shows the kinetics of nitrate adsorption on Purolite A520E at two resin concentrations using HSDM, pseudo-first-order and pseudo-second-order models. All three models predicted the experimental data very well as seen from the very high $R^{2}$ values (Table 1 ). Furthermore, the values of $q_{\mathrm{e}}$ calculated from pseudo-first-order and pseudosecond-order kinetic models were almost similar to the experimental value of $q_{\mathrm{e}}$ (Table 1 ). The results show that any of the three models can be used in design consideration.
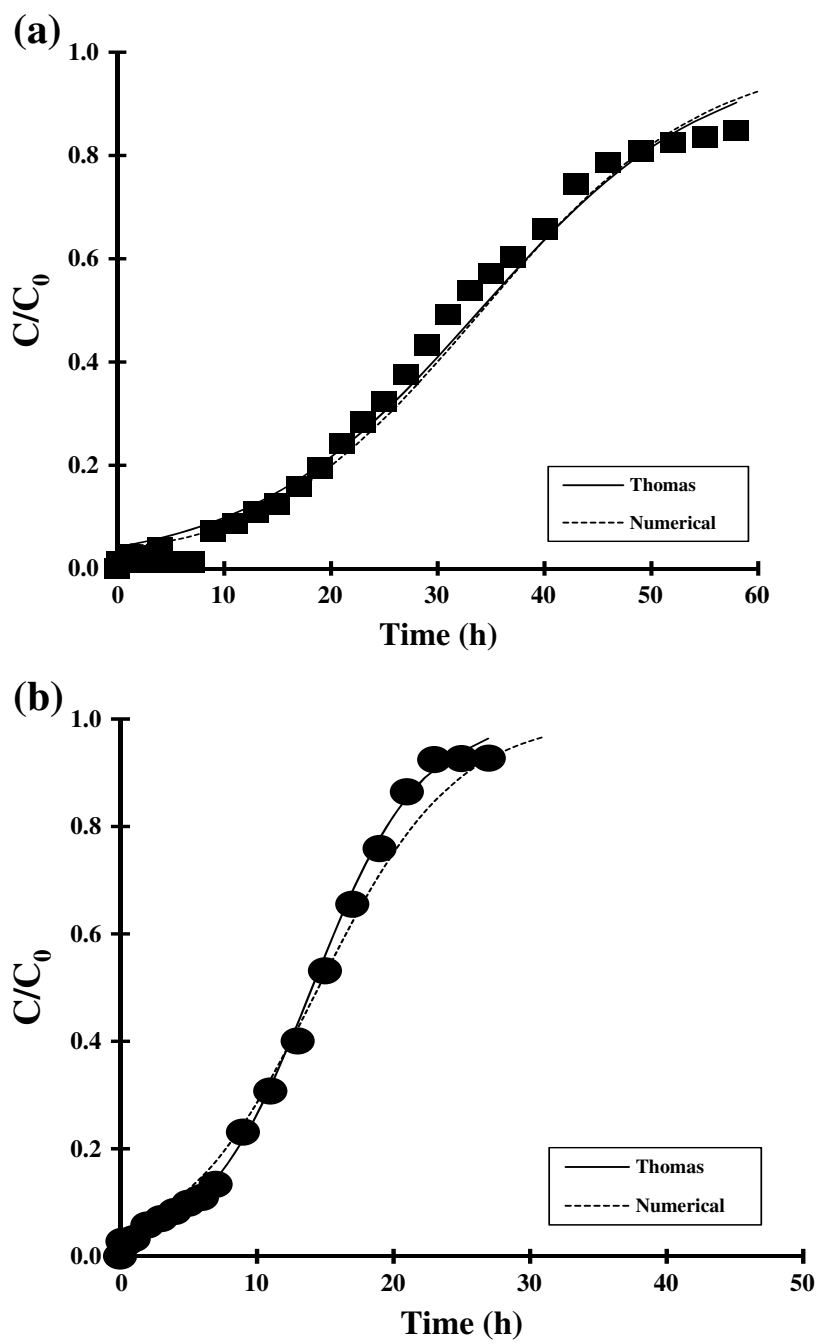

Fig. 4 Experimental breakthrough curves for the filtration velocities a $2.5 \mathrm{~m} / \mathrm{h}$ and $\mathbf{b} 5.0 \mathrm{~m} / \mathrm{h}$ and model simulation curves for Purolite A520E (bed height $=12 \mathrm{~cm}$ and initial nitrate concentration $=20 \mathrm{mg} \mathrm{N} / \mathrm{L}$ ). Experimental values are shown by data points, and model predictions are represented by lines 
The HSDM results show that the surface diffusion $D_{\mathrm{s}}$ was higher at lower resin concentration, which indicates that the surface diffusion $D_{\mathrm{s}}$ is a function of the equilibrium concentration $C_{\mathrm{e}}$. This agreed with the findings of Ahmad et al. (2012) where increase in equilibrium concentration, $C_{\mathrm{e}}$ increased the value of $D_{\mathrm{s}}$ for organic matter adsorption on Purolite A500PS.

\section{Fixed-bed column studies}

As expected, the breakthrough of nitrate in the column generally occurred faster with higher filtration rate (Fig. 3). When the inlet filtration rate was $5.0 \mathrm{~m} / \mathrm{h}$, the plateau of $C_{t} /$ $C_{0}$ occurred within $23 \mathrm{~h}$ of operation $(958 \mathrm{BV})$ and the value of $C_{t} / C_{0}$ was 0.92 . The time to reach the plateau of $C_{t} / C_{0}$ increased significantly with a decrease in the filtration rate. The saturation time was increased to $52 \mathrm{~h}$ (1083 $\mathrm{BV}$ ) for the inlet flow rate of $2.5 \mathrm{~m} / \mathrm{h}$, and the value of $C_{t} /$ $C_{0}$ was 0.82 . The faster breakthrough exhibited by the higher flow rate is due to faster movement of the adsorbent zone along the bed, reducing the contact time between nitrate and the ion exchange resin. The gradual breakthrough at the lower flow rate suggested longer residence time of nitrate in the column. Similar trends have been reported for nitrate removal by another ion exchange resin (Hekmatzadeh et al. 2012) and an amine-cross-linked wheat straw (Xu et al. 2010) and $\mathrm{Cr}(\mathrm{VI})$ removal by a fungal biomass (Verma et al. 2014).

\section{Fixed-bed column modelling}

The Thomas model and numerical model fits to experimental data were very good as seen from the very high $R^{2}$ values $\left(R^{2} \geq 0.96\right)$ (Table 2 ; Fig. 3 ).

\section{Thomas model}

The $k_{\mathrm{T}}$ and $q_{\mathrm{o}}$ values obtained from the Thomas model are presented in Table 2. Increase in flow rate decreased the adsorption capacity $\left(q_{\mathrm{o}}\right)$, which has also been reported elsewhere for other adsorbents (Aksu and Gonen 2004; Ahmad and Hameed 2010). The values obtained for nitrate adsorption capacity of 9.69 and $8.22 \mathrm{mg} \mathrm{N} / \mathrm{g}$ for the lower and higher flow rates, respectively, are approximately the same as those determined by manual calculation (Eqs. 6, 7) from the breakthrough curves (13.5 and $12.0 \mathrm{mg} \mathrm{N} / \mathrm{g}$ for the lower and higher flow rates, respectively). However, these values are lower than the Langmuir adsorption capacity of $32.2 \mathrm{mg} \mathrm{N} / \mathrm{g}$ obtained in batch study. The primary reason for lower adsorption capacity values in the column experiment compared to the Langmuir adsorption value is that flow through adsorption column is not in equilibrium unlike in batch experiments. Another reason is that column adsorption was determined at a lower solution nitrate concentration than the nitrate concentration at which Langmuir adsorption maximum was determined.

\section{Numerical model}

The effect of filtration velocity on the breakthrough curves for the adsorption of nitrate on Purolite A520E is depicted in Fig. 4, and the values of kinetic parameters $\left(D_{\mathrm{L}}, k_{\mathrm{f}}\right.$ and $\left.D_{\mathrm{S}}\right)$ for different conditions are presented in Table 2. The breakthrough time of nitrate was higher at lower filtration velocity. However, the higher the filtration velocity, the smaller is the external mass transfer resistance, which leads to narrower mass transfer zone and sharper breakthrough curves. The model predicts reasonably well the experimental results as shown in Fig. 4 and by the very high $R^{2}$ values $\left(R^{2}=0.98\right.$, 0.99; Table 2). Macroscopically, when the filtration velocity increases, the residence time in the bed decreases, and this leads to less bed utilization. Therefore, the breakthrough time and the bed capacity will decrease with increasing filtration velocity. Microscopically, it is expected that the change of filtration velocity will affect the film diffusion, but not the intraparticle diffusion. The higher the filtration velocity, the smaller the film resistance and a larger $\mathrm{k}_{\mathrm{f}}$ results (Danny et al. 2001). The intraparticle diffusion coefficient $\left(D_{\mathrm{s}}\right)$ values for the two filtration velocities were approximately the same (Table 2), showing that the change in filtration velocity does not affect the rate of intraparticle diffusion $\left(D_{\mathrm{s}}\right)$, which is similar to the results reported by Danny et al. (Danny et al. 2001) for copper and cadmium adsorption on bone char. In contrast to the intraparticle diffusion coefficient $\left(D_{\mathrm{s}}\right)$, the axial dispersion coefficient, $D_{\mathrm{L}}$ increased with filtration velocity as also observed by Hekmatzadeh et al. (2012) for nitrate adsorption on an ion exchange resin. Hekmatzadeh et al. (2012) explained the increase in $D_{\mathrm{L}}$ with filtration velocity as being caused by the increase in interstitial flow velocity.

\section{Conclusion}

Of the four anion exchange resins tested in the batch study, Purolite A520E had the highest nitrate removal capacity. The kinetics of nitrate adsorption by Purolite A520E in the batch study was satisfactorily described by pseudo-first- 
order, pseudo-second-order and HSDM models. The empirical Thomas model and a numerical model based on advection-dispersion equation satisfactorily described nitrate adsorption behaviour in a fixed-bed column containing Purolite A520E at two filtration velocities. The breakthrough curve was steeper and breakthrough occurred faster for the higher filtration rate. The experimental and Thomas model predicted breakthrough adsorption capacities (12.0-13.5 and 8.2-9.7 mg N/g, respectively) agreed well. However, the Langmuir adsorption maximum calculated from the batch study (32.2 $\mathrm{mg} \mathrm{N} / \mathrm{g}$ ) was much higher than the column values.

Acknowledgments This work was funded by Australian Research Council Discovery Research Grant (DP 1092603). The authors thank Vitachem for supplying Purolites.

\section{References}

Ahmad AA, Hameed BH (2010) Fixed bed adsorption of reactive azo dye onto granular activated carbon prepared from waste. J Hazard Mater 175:298-303

Ahmad RT, Nguyen TV, Shim WG, Vigneswaran S, Moon H, Kandasamy J (2012) Effluent organic matter removal by Purolite ${ }^{\circledR}$ A500PS: experimental performance and mathematical model. Sep Purif Technol 98:46-54

Aksu Z, Gonen F (2004) Biosorption of phenol by immobilized activated sludge in a continuous packed bed: prediction of breakthrough curves. Process Biochem 39:599-613

Aliabadi M, Khazaei I, Fakhraee H, Mousavian MTH (2012) Hexavalent chromium removal from aqueous solution by using low-cost biological wastes: equilibrium and kinetic studies. Int $\mathbf{J}$ Environ Sci Technol 9:319-326

Awual MR, Urata S, Jyo A, Tamada M, Katakai A (2008) Arsenate removal from water by a weak-base anion exchange fibrous adsorbent. Water Res 42:689-696

Awual MR, Hossain MA, Shenashen MA, Yaita T, Suzuki S, Jyo A (2013) Evaluating of arsenic (V) removal from water by weakbase anion exchange adsorbents. Environ Sci Pollut Res 20:421-430

Bhatnagar A, Sillanpää M (2011) A review of emerging adsorbents for nitrate removal from water. Chem Eng J 168:493-504

Brown PN, Byrne GD, Hindmarsh AC (1989) VODE: a variable coefficient ODE solver. SIAM J Sci Stat Comput 10:1038-1051

Bulgariu L, Ceica A, Lazar L, Cretescu I, Balasanian I (2010) Equilibrium and kinetics study of nitrate removal from water by Purolite A100 resin. Rev Chim 61:1136-1141

Chiu HF, Tsai SS, Yang CY (2007) Nitrate in drinking water and risk of death from bladder cancer: an ecological case-control study in Taiwan. J Toxicol Environ Health 70:1000-1004

Danny DK, Ko KF, Porter JF, McKay G (2001) Film pore diffusion model for the fixed-bed sorption of copper and cadmium ions onto bone char. Water Res 35:3876-3886

Fatima T, Nadeem R, Masood A, Saeed R, Ashraf M (2013) Sorption of lead by chemically modified rice bran. Int J Environ Sci Technol 10:1255-1264

Fewtrell L (2004) Drinking-water nitrate, methemoglobinemia, and global burden of disease: a discussion. Environ Health Perspect 112:1371-1374
Gu B, Ku Y-K, Jardine PM (2004) Sorption and binary exchange of nitrate, sulphate and uranium on an anion-exchange resin. Eniron Sci Technol 38:3184-3188

Guo WS, Shim WG, Vigneswaran S, Ngo HH (2005) Effect of operating parameters in a submerged membrane adsorption hybrid system: experiments and mathematical modelling. J Membr Sci 247:65-67

Hekmatzadeh AA, Karimi-Jashani A, Talebbeydokhti N, Klove B (2012) Modeling of nitrate removal for ion exchange resin in batch and fixed bed experiments. Desalination 284:22-31

Helfferich F (1995) Ion exchange. McGraw-Hill, New York

WHO (2006) Guidelines for drinking-water quality. World Health Organization, Geneva

Ho YS, McKay G (1999) Pseudo-second order model for sorption processes. Process Biochem 34:451-465

Hoek JP, Hoek WF, Klapwijk A (1988) Nitrate removal from ground water-use of a nitrate selective resin and a low concentrated regenerant. Water Air Soil Pollut 37:41-53

Johir MAH, George J, Vigneswaran S, Kandasamy J, Grasmick A (2011) Removal and recovery of nutrients by ion exchange from high rate membrane bio-reactor (MBR) effluent. Desalination 275:197-202

Kapoor A, Viraraghavan T (1997) Nitrate removal from drinking water-review. J Environ Eng 123:371-380

Loganathan P, Vigneswaran S, Kandasamy J, Bolan NS (2014) Removal and recovery of phosphate from water using sorption. Crit Rev Environ Sci Technol. doi:10.1080/10643389.2012. 741311

Najm IN (1996) Mathematical modeling of PAC adsorption processes. J Am Water Works Assoc 88:79-89

Nur T, Johir MAH, Loganathan P, Vigneswaran S, Kandasamy J (2012) Effectiveness of purolite A500PS and A520E ion exchange resins on the removal of nitrate and phosphate from synthetic water. Desalin Water Treat 47:50-58

Nur T, Johir MAH, Loganathan P, Nguyen T, Vigneswaran S, Kandasamy J (2014) Phosphate removal from water using an iron oxide impregnated strong base anion exchange resin. J Ind Eng Chem. doi:10.1016/j.jiec.2013.07.009

Orlando US, Baes AU, Nishijima W, Okada M (2002) Preparation of agricultural residue anion exchangers and its nitrate maximum adsorption capacity. Chemosphere 48:1041-1046

Phillips DH, Gu B, Watson DB, Parmele CS (2008) Uranium removal from contaminated groundwater by synthetic resins. Water Res 42:260-268

Pintar A, Batista J, Levec J (2001) Integrated ion exchange/catalytic process for efficient removal of nitrates from drinking water. Chem Eng Sci 56:1551-1559

Primo O, Rivero M, Urtiaga A, Ortiz I (2009) Nitrate removal from electro-oxidized landfill leachate by ion exchange. J Hazard Mater 164:389-393

Purolite (2013) www.purolite.com. Technical data, ISO 9002. Accessed March 2013

Ruthven DM (1984) Principles of adsorption and adsorption processes. Wiley, New York

Samatya S, Kabay N, Yuksel U, Arda M, Yuksel M (2006) Removal of nitrate from aqueous solution by nitrate selective ionexchange resins. React Funct Polym 66:1206-1214

Sigmaaldrich (2013) www.sigmaaldrich.com. Accessed March 2013 Thomas HC (1944) Heterogeneous ion exchange in a flowing system. J Am Chem Soc 66:1664-1666

Valincius G, Niaura G, Kazakevičieneù B, Talaikyteù Z, Kažemeù kaiteù M, Butkus E, Razumas V (2004) Anion effect on mediated electron transfer through ferrocene-terminated selfassembled monolayers. Langmuir 20:6631-6638 
Verma DK, Hasan SH, Ranjan D, Banik RM (2014) Modified biomass of Phanerochaete chrysosporium immobilized on luffa sponge for biosorption of hexavalent chromium. Int $\mathbf{J}$ Environ Sci Technol. doi:10.1007/3/3762-013-0345-6

Villadsen J, Stewart WE (1967) Solution of boundary value problems by orthogonal collocation. Chem Eng Sci 22:1483-1501
Xu X, Gao BY, Yue GY, Zhong QQ (2010) Preparation of agricultural by-product based anion exchanger and its utilization for nitrate and phosphate removal. Bioresour Technol 101:8558-8564

Zagorodni AA (2007) Ion exchange materials properties and applications. Elsevier BV, Amsterdam 